\title{
Prone positioning and extracorporeal membrane oxygenation for severe acute respiratory distress syndrome: time for a randomized trial?
}

\author{
Christophe Guervilly ${ }^{1,2^{*}} \mathbb{0}$, Eloi Prud'homme1, Vanessa Pauly², Jérémie Bourenne ${ }^{3}$, Sami Hraiech ${ }^{2,4}$, \\ Florence Daviet ${ }^{1}$, Mélanie Adda ${ }^{1}$, Benjamin Coiffard ${ }^{1,2}$, Jean Marie Forel ${ }^{1,2}$, Antoine Roch ${ }^{1,2,4}$, Nicolas Persico ${ }^{4}$ \\ and Laurent Papazian ${ }^{1,2}$
}

(c) 2019 Springer-Verlag GmbH Germany, part of Springer Nature

\section{Dear Editor,}

The recently published EOLIA study [1] has failed to demonstrate a $20 \%$ increase in survival in patients with very severe acute respiratory distress syndrome (ARDS) using a strategy of early application of veno-venous extracorporeal membrane oxygenation (vvECMO) as compared with low-volume, low-pressure ventilation in combination with rescue therapies including prone positioning (PP), inhaled nitric oxide and neuromuscular blockers. Early, prolonged and repeated sessions of prone positioning (PP) are associated with a substantial outcome benefit in ARDS patients, with a $\mathrm{PaO}_{2} / \mathrm{FiO}_{2}$ ratio $<150 \mathrm{mmHg}$ [2]. In the EOLIA trial, there was a difference in the use of PP between the two arms, with $90 \%$ of the patients in the control group turned to PP before and/or after randomization, and only $66 \%$ of the patients in the ECMO group.

Therefore, we have performed a retrospective observational study to compare outcomes of severe ARDS patients under vvECMO according to the use of PP or lack thereof during their ECMO run in order to assess the potential justification for further randomized clinical trials.

A flow chart, ECMO criteria, management of vvECMO and mechanical ventilation are described in the ESM. We

\footnotetext{
*Correspondence: christophe.guervilly@ap-hm.fr

${ }^{1}$ Medical Intensive Care Unit North Hospital, APHM, Marseille, France

Full author information is available at the end of the article
}

have compared patients with a combination of PP during ECMO (prone ECMO group) to those maintained in supine position (ECMO alone group). See statistical details in the ESM.

During the study period, 168 patients were supported by vvECMO for severe ARDS and were included in the analysis. The main pre-ECMO characteristics and outcomes are presented in Table 1. Among the patients, 91 (54\%) were placed at least once in prone position during the ECMO run, whereas 77 (46\%) were maintained in supine position during ECMO. Patients in the prone ECMO group were more frequently turned to PP before ECMO. Patients underwent a mean of three PP sessions, with a range from 1 to 17 . Patients in the prone ECMO group were more likely to be weaned from ECMO. Accordingly, 30-day, 60-day and 90-day survival rates were significantly higher.

To reduce the risk of bias (indication for PP, severity of illness), we duplicated the comparisons with matching according to age, sex, SOFA, prior duration of mechanical ventilation and prior PP before ECMO. We also found a higher rate of ECMO weaning and better survival rates in a comparative matched study of 50 pairs of patients (see ESM). However, we cannot exclude residual confounding factors that overestimate the effect.

Aside from its positive effects on oxygenation, PP can reduce ventilator-induced lung injury in ARDS patients under ECMO [3, 4]. A further randomized controlled trial should be performed in patients with severe ARDS supported by vvECMO with implementation of 
Table 1 Demographic characteristics, pre-ECMO treatments, ECMO and mechanical ventilation settings and outcomes of patients

\begin{tabular}{|c|c|c|c|c|}
\hline & $\begin{array}{l}\text { All patients } \\
(n=168)\end{array}$ & $\begin{array}{l}\text { ECMO alone } \\
(n=77)\end{array}$ & $\begin{array}{l}\text { Prone ECMO } \\
(n=91)\end{array}$ & $P$ value \\
\hline Age (years), mean $\pm S D$ & $51 \pm 14$ & $53 \pm 13$ & $49 \pm 15$ & 0.13 \\
\hline Male sex, $n(\%)$ & $118(70)$ & $52(67)$ & $66(72)$ & 0.48 \\
\hline SOFA score at cannulation, mean \pm SD & $10 \pm 4$ & $11 \pm 4$ & $10 \pm 4$ & 0.27 \\
\hline Mechanical ventilation before ECMO (days), mean \pm SD & $5 \pm 6$ & $6 \pm 7$ & $5 \pm 5$ & 0.32 \\
\hline $\mathrm{PaO}_{2}$ to $\mathrm{FiO}_{2}$ ratio before $\mathrm{ECMO}(\mathrm{mmHg})$, mean $\pm \mathrm{SD}$ & $67 \pm 20$ & $67 \pm 19$ & $67 \pm 21$ & 0.94 \\
\hline Prone position before $\mathrm{ECMO}, n(\%)$ & $108(64)$ & $39(50)$ & $69(76)$ & 0.001 \\
\hline iNO before ECMO, $n(\%)$ & $62(37)$ & $31(40)$ & $31(34)$ & 0.44 \\
\hline Mobile ECMO team, $n(\%)$ & $118(70)$ & $52(67)$ & $66(72)$ & 0.48 \\
\hline \multicolumn{5}{|c|}{ Mechanical ventilation settings the first day of ECMO, mean \pm SD } \\
\hline Tidal volume $(\mathrm{mL})$ & $175 \pm 60$ & $167 \pm 52$ & $180 \pm 63$ & 0.15 \\
\hline Plateau airway pressure $\left(\mathrm{cm} \mathrm{H}_{2} \mathrm{O}\right)$ & $24 \pm 4$ & $24 \pm 4$ & $24 \pm 4$ & 0.44 \\
\hline $\operatorname{PEEP}\left(\mathrm{cmH}_{2} \mathrm{O}\right)$ & $15 \pm 3$ & $14 \pm 4$ & $15 \pm 3$ & 0.36 \\
\hline Driving pressure $\left(\mathrm{cmH}_{2} \mathrm{O}\right)$ & $10 \pm 4$ & $10 \pm 4$ & $10 \pm 4$ & 0.92 \\
\hline Respiratory rate (cycles/min) & $11 \pm 2$ & $11 \pm 2$ & $11 \pm 2$ & 0.95 \\
\hline Respiratory system compliance $\left(\mathrm{mL} / \mathrm{cmH}_{2} \mathrm{O}\right)$ & $21 \pm 11$ & $21 \pm 11$ & $22 \pm 12$ & 0.54 \\
\hline Inspired fraction of oxygen (\%) & $75 \pm 24$ & $74 \pm 24$ & $76 \pm 25$ & 0.63 \\
\hline \multicolumn{5}{|l|}{$\mathrm{ECMO}$ settings, the first day of ECMO, mean $\pm S D$} \\
\hline ECMO blood flow (L/min) & $4.2 \pm 0.7$ & $4.1 \pm 0.7$ & $4.3 \pm 0.7$ & 0.17 \\
\hline Sweep gas flow (L/min) & $5 \pm 2$ & $5 \pm 2$ & $5 \pm 2$ & 0.80 \\
\hline Membrane lung fraction of oxygen (\%) & 100 & 100 & 100 & 1 \\
\hline Number of prone session during $\mathrm{ECMO}$, mean $\pm \mathrm{SD}$ & $1.5 \pm 2.5$ & - & $3 \pm 3$ & - \\
\hline ECMO weaning, $n(\%)$ & $103(61)$ & $39(50)$ & $64(70)$ & 0.009 \\
\hline Duration of ECMO (days), mean \pm SD & $15 \pm 13$ & $9 \pm 8$ & $20 \pm 14$ & $<0.001$ \\
\hline $\mathrm{ECMO}$ free days at day 60 , mean $\pm \mathrm{SD}$ & $22 \pm 23$ & $19 \pm 25$ & $24 \pm 22$ & 0.30 \\
\hline Ventilator-free days at day 60 , mean $\pm S D$ & $15 \pm 19$ & $13 \pm 20$ & $16 \pm 18$ & 0.19 \\
\hline ICU length of stay (days), mean \pm SD & $29 \pm 25$ & $20 \pm 18$ & $36 \pm 28$ & $<0.001$ \\
\hline 30-day survival, $n(\%)$ & $98(58)$ & $33(43)$ & $65(71)$ & $<0.001$ \\
\hline 60-day survival, $n$ (\%) & $88(52)$ & $31(40)$ & $57(62)$ & 0.004 \\
\hline 90-day survival, $n$ (\%) & $82(49)$ & $29(38)$ & $53(58)$ & 0.008 \\
\hline
\end{tabular}

Values are expressed as mean $\pm S D$, proportions as $n(\%)$

ECMO extracorporeal membrane oxygenation, SOFA sepsis-related organ failure assessment, $i N O$ inhaled nitric oxide, ICU intensive care unit, PEEP positive endexpiratory pressure

systematic PP in one arm. Such a trial would be faced with predictable challenges related to the small number of centres trained in prone-positioning of patients on ECMO and the relatively low percentage of eligible patients after exclusion of contraindications for PP. Determining the best timing and duration of PP in ECMO requires further investigation.

\section{Electronic supplementary material}

The online version of this article (https://doi.org/10.1007/s00134-019-05570-9) contains supplementary material, which is available to authorized users.

\section{Author details}

${ }^{1}$ Medical Intensive Care Unit North Hospital, APHM, Marseille, France. ${ }^{2}$ CEReSS, Center for Studies and Research On Health Services and Quality of Life EA3279, Aix-Marseille University, Marseille, France. ${ }^{3}$ Medical and Emergency
Resuscitation, La Timone 2 University Hospital, Aix-Marseille University, Marseille, France. ${ }^{4}$ Emergency Department, North Hospital, APHM, Marseille, France.

\section{Acknowledgements}

The authors would like to thank all the ICU nursing staff and the perfusionist's team.

\section{Compliance with ethical standards}

\section{Conflicts of interest}

The authors declare that they have no conflicts of interest.

\section{Ethical statement}

According to the French legislation, because of the retrospective design of the study, no inform consent is warranted. The study was registered by the French authority Commission Nationale Informatique et Libertés under the number: CIL/APHM 2018-44. 


\section{Publisher's Note}

Springer Nature remains neutral with regard to jurisdictional claims in published maps and institutional affiliations.

\section{Accepted: 13 February 2019}

Published online: 5 March 2019

\section{References}

1. Combes A, Hajage D, Capellier G, Demoule A, Lavoué S, Guervilly C, Da Silva D, Zafrani L, Tirot P, Veber B, Maury E, Levy B, Cohen Y, Richard C, Kalfon P, Bouadma L, Mehdaoui H, Beduneau G, Lebreton G, Brochard L, Ferguson ND, Fan E, Slutsky AS, Brodie D, Mercat A, EOLIA Trial Group, REVA, and ECMONet (2018) Extracorporeal membrane oxygenation for severe acute respiratory distress syndrome. N Engl J Med 378:1965-1975
2. Guérin C, Reignier J, Richard JC, Beuret P, Gacouin A, Boulain T, Mercier E, Badet M, Mercat A, Baudin O, Clavel M, Chatellier D, Jaber S, Rosselli S, Mancebo J, Sirodot M, Hilbert G, Bengler C, Richecoeur J, Gainnier M, Bayle F, Bourdin G, Leray V, Girard R, Baboi L, Ayzac L, PROSEVA Study Group (2013) Prone positioning in severe acute respiratory distress syndrome. N Engl J Med 368:2159-2168

3. Gattinoni L, Taccone P, Carlesso E, Marini JJ (2013) Prone position in acute respiratory distress syndrome. rationale, indications, and limits. Am J Respir Crit Care Med 188:1286-1293

4. Albert RK, Keniston A, Baboi L, Ayzac L, Guérin C, Proseva Investigators (2014) Prone position-induced improvement in gas exchange does not predict improved survival in the acute respiratory distress syndrome. Am J Respir Crit Care Med 189:494-496 